\title{
RODA DE CONVERSA VIRTUAL: DIÁLOGOS ENTRE OS SABERES SOBRE O DESENVOLVIMENTO INFANTIL
}

\section{VIRTUAL CONVERSATION CIRCLE: DIALOGUES WITH THE KNOWLEDGE ABOUT CHILD DEVELOPMENT}

\author{
Raquel Costa Albuquerque* \\ ORCID: https://orcid.org/0000-0002-3359-7996 \\ Juliana Fonsêca de Queiroz Marcelino** \\ ORCID: https://orcid.org/0000-0003-2961-3292 \\ Maria Luísa de Sá Peregrino Arrais*** \\ ORCID: https://orcid.org/0000-0001-5721-9183 \\ Lais Rafaely da Silva Soares**** \\ ORCID: https://orcid.org/0000-0002-7371-9708 \\ Lucas de Paiva Silva**** \\ ORCID: https://orcid.org/0000-0003-4258-6591
}

\section{Resumo}

Objetivou-se apresentar a criação e execução, até os dias atuais, do projeto de extensão: "Roda de Conversa Virtual: Dialogando entre os Saberes sobre o Desenvolvimento Infantil". Trata-se de uma ação que se caracteriza como projeto de extensão, na qual acontece uma reunião interna, entre docentes e discentes envolvidos no projeto para planejamento, tendo como produtos sugestões e definição de tema da roda de conversa e indicação do profissional que será convidado a participar. Como resultados, até o momento 16 rodas de conversa foram realizadas, salvas no YouTube do projeto de extensão. Conclui-se que a extensão universitária é um compromisso de troca de saberes da universidade com a comunidade e, apesar do novo cenário que nos desafia e nos faz repensar na criação de ações inovadoras na extensão, é possível realizar um processo contínuo de ensino-aprendizagem virtual, visando a futura aplicação prática do conhecimento teórico adquirido.

Palavras-chave: Aprendizagem; Desenvolvimento Infantil; Terapia Ocupacional.

\begin{abstract}
This study aims to present the creation and implementation, to this day, of the outreach project "Virtual Conversation Circle: Dialogues with the Knowledge about Child Development". It is an outreach project in which is held a meeting among teachers and students who are involved in the project to plan, discuss and choose the theme of the conversation circle and the professional who will be invited to participate. So far, 16 conversation circles have been held and are available online through the outreach project account at You Tube. It is concluded that an outreach action at a university is a commitment to exchange knowledge between the university and the community. Thus, despite the new scenario, which challenges us and makes us to consider the creation and implementation of innovative outreach actions, it is possible to carry out a continuous process of virtual teaching-learning, aiming at the future practical application of the theoretical knowledge acquired.
\end{abstract}

Keywords: Child Development; Learning; Occupational Therapy.

Data recebimento: $21 / 07 / 2021$

Data de aceite: $20 / 10 / 2021$
* Professora da Universidade Federal de Pernambuco (UFPE), Recife - PE, Brasil. E-mail: raquel.albuquerque@ufpe.com.br ** Professora da Universidade Federal de Pernambuco (UFPE), Recife - PE, Brasil. E-mail: julifons@yahoo.com.br *** Aluna de Graduação da Universidade Federal de Pernambuco (UFPE), Recife - PE, Brasil. E-mail: luisa.arrais@ufpe.br **** Aluna de Graduação da Universidade Federal de Pernambuco (UFPE), Recife - PE, Brasil. E-mail: lais.rafaely@ufpe.br ***** Aluno de Mestrado do Instituto de Medicina Integral Professor Fernando Figueira (IMIP), Recife - PE, Brasil. E-mail: lucaspaiva.to@gmail.com 


\section{Introdução}

Terapeutas ocupacionais consideram, em suas intervenções, as ocupações nas quais o indivíduo se envolve, entendendo que a identidade do sujeito reflete as experiências vividas durante toda a vida (FOLHA; BARBA, 2020). Assim, os papéis ocupacionais desenvolvidos e experiências vivenciadas no decorrer da infância resultam em aprendizagens que influenciam nos futuros relacionamentos e princípios morais e sociais (EMMEL; FIGUEREDO, 2011).

Ainda sobre as ocupações e a terapia ocupacional, pesquisadores afirmam que, para esses profissionais, as ocupações humanas infantis são entendidas como ações realizadas intencionalmente pelas crianças e que acontecem ao longo do seu desenvolvimento. Sendo assim, a realização dessas ocupações contribui para o desenvolvimento cognitivo, físico, social e afetivo da criança, influenciando diretamente na saúde global dela, como também no seu bemestar (MANDICH; RODGER, 2006; DUNFORD; BANNIGAN, 2011; ASBJØRNSLETT; ENGELSRUD; HELSET, 2015).

Define-se como desenvolvimento o processo de mudanças nas estruturas físicas e neurológicas, cognitivas e comportamentais (MUSSEN et al., 1977). Então, o desenvolvimento infantil é multifatorial, consequência da união de fatores biológicos, ambientais, familiares e sociais (HALPERN et al., 2000).

Do nascimento até 2 anos de idade, em especial, o desenvolvimento neuromotor ocorre em maior escala, permitindo à criança aumento da capacidade cognitiva e motora, tornandoa, portanto, mais suscetível a agravos (KING; GLASCOE, 2003).

Diante da atenção à saúde e desenvolvimento infantil, é necessário que o profissional, ou ainda discente de Terapia Ocupacional, possua um embasamento teórico de suporte que facilite identificar a observação dos cuidadores, da criança e do ambiente onde está inserida, entendendo que a infância deve acontecer de forma saudável, fora da rotulação da dificuldade e/ou deficiência que pode ser apresentada pela criança (BARBA et al., 2017).

Deste modo, dando a necessária importância ao desenvolvimento do conhecimento do futuro profissional da Terapia Ocupacional no seu processo de aprendizagem, espera-se que ações que integrem o ensino, a pesquisa e a extensão façam parte desta formação, tendo em vista ser a infância um vasto campo de pesquisa e atuação do terapeuta ocupacional (AZEVEDO; BARBA, 2017).

Portanto, nota-se que é possível e necessário que, desde a trajetória acadêmica, sejam abordados assuntos complementares para a formação profissional dos alunos, como comteúdos como a promoção de saúde infantil em contextos escolares; o acompanhamento e apoio a familiares de recém-nascidos internados nas Unidades de Terapias Intensivas Neonatais (UTIN); o desenvolvimento da percepção visual do neonatal, dentre outros assuntos que comtribuem para o suporte teórico da comunidade acadêmica para o futuro profissional terapeuta ocupacional (FOLHA; CARVALHO, 2017; ALBUQUERQUE et al., 2019; CORREIA; ROCHA, 2019).

Em razão da pandemia causada pelo novo coronavírus (COVID-19), os governos em todo o mundo estabeleceram o isolamento social como medida para prevenir o contágio em massa, afetando bruscamente o setor educacional/universitário, que tiveram suas atividades acadêmicas suspensas por tempo indeterminado (BBC, 2020). Deste modo, iniciativas de 
continuidade e/ou criação de espaços para discussão online mostram-se mais presentes, como uma importante ferramenta de alcance ao público nas redes virtuais nos dias atuais, sendo a roda de conversa virtual um exemplo possível.

Diante dessa preocupação em relação aos estudantes universitários e os impactos e prejuízos que o isolamento social pudesse causar, muitos coordenadores de Departamentos das Universidades, docentes e monitores tentaram manter um contato virtual com os alunos matriculados em disciplinas ou que estivessem inseridos em projetos de pesquisa e extensão, visando a manutenção das relações universitárias, para que o processo de readaptação no período de volta às aulas, com as possíveis precauções e distanciamento, pudesse ser o menos impactante possível para toda a comunidade acadêmica.

O Plano Nacional de Extensão, publicado em 2000, caracteriza a extensão universitária como "o processo educativo, cultural e científico que articula o Ensino e a Pesquisa de forma indissociável e viabiliza a relação transformadora entre a Universidade e a Sociedade", sendo a extensão um acréscimo à educação para além dos muros da universidade.

Para a idealização do projeto de extensão aqui apresentado, entendeu-se enquanto "roda de conversa" o conceito defendido por Moura e Lima (2014, p. 28) de "um método de participação coletiva de debate acerca de determinada temática em que é possível dialogar com os sujeitos, que se expressam, escutam seus pares e a si mesmos pelo exercício reflexivo.”. A proposta de um diálogo aberto reflete o objetivo da socialização de ideias e conhecimentos, a troca de vivências e o compartilhamento de informações sobre determinado tema em foco.

Foi através disso e na perspectiva de ampliação e aprofundamento do conhecimento científico que surgiu o projeto de extensão "Roda de Conversa Virtual: Dialogando entre os Saberes sobre o Desenvolvimento Infantil", criado por uma professora coordenadora da disciplina de Terapia Ocupacional na Infância, do Departamento de Terapia Ocupacional da Universidade Federal de Pernambuco (UFPE), juntamente com três monitoras da mesma disciplina acadêmica, com proposta pedagógica virtual de ensino-aprendizagem, capaz de abordar conteúdos e aspectos sobre a infância, a saúde da criança e seus contextos.

O projeto tem como proposta promover o diálogo entre profissionais terapeutas ocupacionais com expertise em desenvolvimento infantil, docentes e alunos de cursos de saúde e educação, profissionais da saúde e educação, pais e cuidadores. Assim, o objetivo deste artigo é apresentar a criação e execução, até os dias atuais, do projeto de extensão: "Roda de Conversa Virtual: Dialogando entre os Saberes sobre o Desenvolvimento Infantil”.

\section{Método}

Para que esse projeto de extensão seja realizado mensalmente, são seguidas algumas etapas. Primordialmente, é realizada uma reunião interna entre docentes responsáveis e discentes envolvidas na organização do projeto, na qual são sugeridos temas para a roda de conversa e, também, definido o profissional que será convidado a participar para trazer seus conhecimentos sobre o assunto. 
Na sequência, é efetuado contato com o profissional indicado, visando a apresentação do projeto, seguido do convite. Caso o profissional se disponha a participar da roda de conversa, é marcada uma reunião com a equipe do projeto de extensão para que seja explicada a forma de funcionamento da roda de conversa. Em seguida, é agendada uma data e horário nos quais o(a) apresentador(a) esteja disponível para abordar e explanar o tema de seu domínio na "Roda de conversa virtual: dialogando entre os saberes sobre o desenvolvimento infantil” (Figura 1).

Figura 1 - Fluxograma do procedimento inicial para a realização da Roda de Conversa do projeto de extensão oda de Conversa Virtual: Dialogando entre os Saberes sobre o Desenvolvimento Infantil”. Recife/PE, maio/2021.

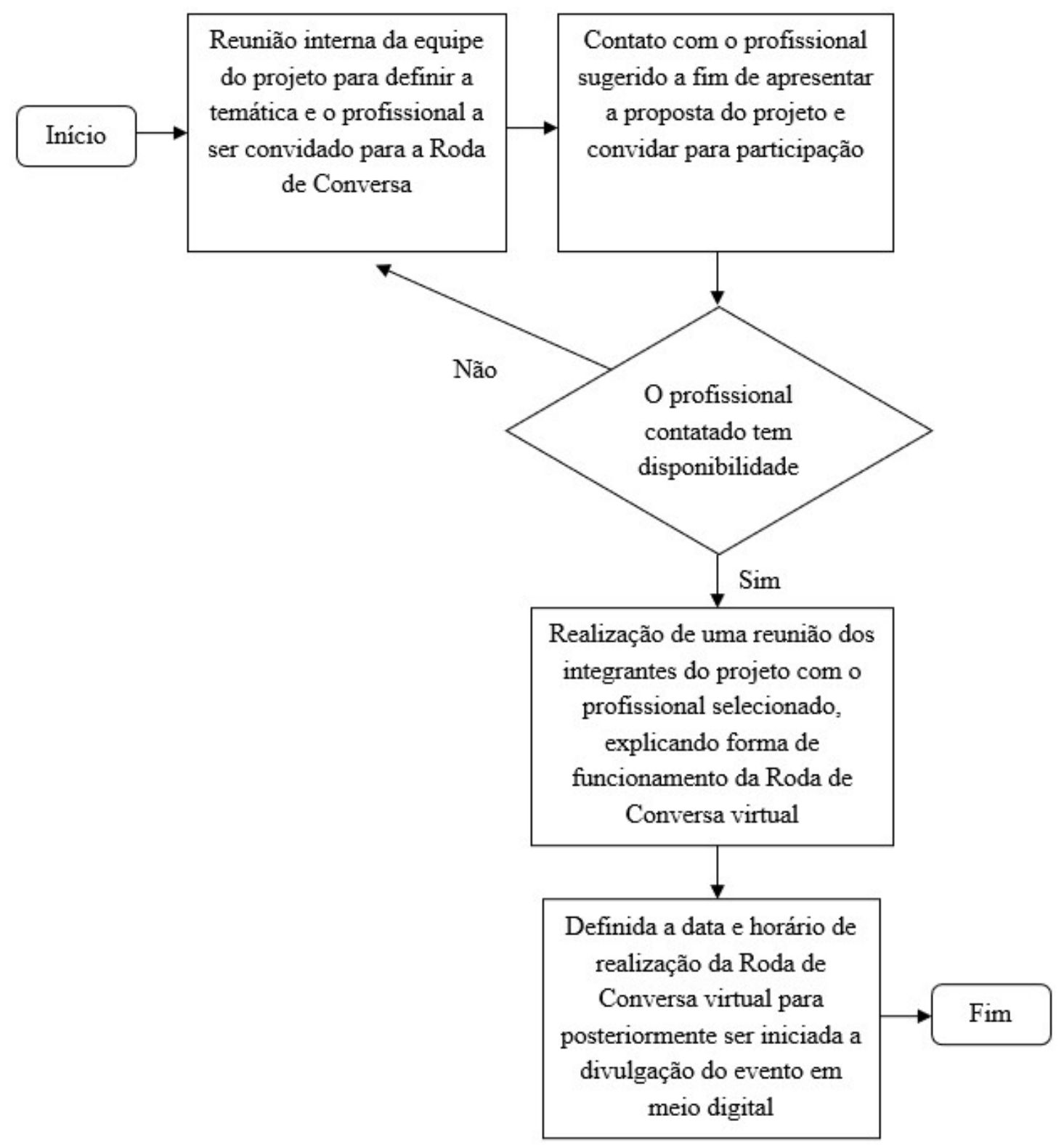

Fonte: Elaboração dos autores, 2021. 
Os profissionais convidados são exclusivamente Terapeutas Ocupacionais, podendo ser docentes ativos ou aposentados, ou profissionais atuantes na área relacionada ao tema. As rodas de conversas virtuais acontecem na plataforma digital Google Meet, por meio de vídeo chamadas com acesso através de um navegador da Web ou aplicativo em dispositivos móveis.

Assim, é gerado um link pela docente coordenadora do projeto, que é divulgado por meio de produto de design (folder digital), acompanhado de texto explicativo sobre o evento, em um grupo do aplicativo WhatsApp e pelas redes sociais do Instagram e Facebook do ComunicaTO ${ }^{\mathrm{i}}$. Essa divulgação acontece cerca de uma semana antes do dia marcado para a realização e é reforçada no dia do acontecimento da roda de conversa virtual.

O Google Meet permite a participação de até 250 pessoas, podendo ser compartilhados slides durante a apresentação, ao passo que a interação de todos os convidados é facilitada através do chat, além da participação por meio do áudio. A plataforma permite fazer a gravação completa da roda de conversa. Além disso, o Google Meet é uma plataforma adquirida pela UFPE que permite a utilização de recursos extra e extensões da própria ferramenta do Google, aos quais docentes e discentes possuem acesso gratuito e sem restrições de uso, via através da utilização dos e-mails institucionais.

Durante a construção deste projeto, foi criado um canal no YouTube ${ }^{\text {ii }}$ exclusivamente para fazer o registro das rodas de conversa, por meio de gravação autorizada pelos participantes no dia do encontro virtual. Além do canal, também foi criado um grupo no WhatsApp para que sejam compartilhadas mais facilmente as rodas de conversa que serão realizadas. $\mathrm{O}$ grupo de WhatsApp também facilita o compartilhamento de materiais didáticos e referências que surjam como sugestão dos palestrantes ou participantes nos encontros virtuais.

No dia da realização do evento, algumas etapas são seguidas. Inicialmente, o profissional é apresentado pela equipe do projeto de extensão aos participantes da roda de conversa. São fornecidos avisos sobre horário de início e término da roda de conversa, incluindo os momentos de trocas, com perguntas e respostas que surgirem durante o encontro. É solicitada, então, a permissão dos participantes para que a roda de conversa seja gravada e registrada com fotos, para que, posteriormente, esse mesmo encontro seja disponibilizado no canal criado na plataforma digital do YouTube. Após o término da roda de conversa, são disponibilizados, no grupo do WhatsApp, materiais de leitura indicados pelo profissional.

O projeto de extensão conta com uma equipe de trabalho assim definida: uma docente do curso de Terapia Ocupacional da UFPE como coordenadora, uma docente também do curso de Terapia Ocupacional UFPE como vice-coordenadora e 3 discentes/monitoras do mesmo curso. Cada componente da equipe tem sua função determinada, acompanhada da respectiva carga horária destinada para cada membro.

Quanto ao público-alvo, no início da atividade de extensão a intenção era de que o público atingido fossem os discentes da disciplina de Terapia Ocupacional na Infância do curso de Terapia Ocupacional da UFPE, sendo também aberto para alunos de outras disciplinas. Contudo, devido à ampla divulgação das rodas de conversa e o interesse em participar, atual- 
mente conta-se com a participação média de 30 pessoas em cada roda de conversa, distribuídas entre discentes, docentes e profissionais terapeutas ocupacionais de várias regiões do país.

\section{Resultados}

Desde o mês de julho de 2020 até maio de 2021, participaram 17 terapeutas ocupacionais palestrantes, de diferentes estados brasileiros, como São Paulo, Pernambuco, Minas Gerais, Rio de Janeiro e Paraná.

O Quadro 1 apresenta, em linhas gerais, os temas já abordados nas rodas de conversa até o presente momento da escrita deste trabalho, bem como suas respectivas durações.

Quadro 1 - Temas abordados nas rodas de conversa virtual entre julho de 2020 e maio de 2021.

\begin{tabular}{|l|c|}
\hline \multicolumn{1}{|c|}{ Rodas de Conversa } & Duração \\
\hline 1. Terapia Ocupacional e o Ser Criativo & $1: 00: 00$ \\
\hline $\begin{array}{l}\text { 2. Terapia Ocupacional e Telessaúde: Continuidade da Reabilitação na Neuropediatria durante } \\
\text { Isolamento Social }\end{array}$ & $1: 59: 33$ \\
\hline 3. A Compreensão Clínica e Emocional da Prematuridade & $2: 19: 25$ \\
\hline 4. Observação do Comportamento Visual em Lactentes & $1: 49: 48$ \\
\hline 5. Terapia Ocupacional e a Inclusão Escolar & $2: 49: 49$ \\
\hline 6. Setting Terapêutico para Crianças com TEA & $1: 35: 34$ \\
\hline 7. Avaliação e Intervenção da Terapia Ocupacional no Brincar & $1: 31: 28$ \\
\hline 8. Brincar: Importância e Desafios & $1: 20: 12$ \\
\hline 9. A Música como Recurso Terapêutico Ocupacional na Assistência à Criança & $1: 32: 10$ \\
\hline 10. Manejo dos Comportamentos Disruptivos de Crianças e Adolescentes Autistas & $1: 23: 33$ \\
\hline 11. Conhecendo o instrumento que avalia a participação ocupacional de crianças e adolescentes & $1: 18: 01$ \\
- SCOPE & $1: 02: 13$ \\
\hline 12. Treinos intensivos de membro superior para criança com Paralisia Cerebral & $1: 21: 03$ \\
\hline 13. Transtorno do desenvolvimento da coordenação: como identificar e lidar com o problema? & $1: 32: 09$ \\
\hline 14. Do processo avaliativo ao raciocínio clínico na terapia ocupacional & $1: 51: 54$ \\
\hline 15. Dificuldades alimentares na infância na perspectiva da terapia ocupacional & $1: 29: 48$ \\
\hline 16. A relação com a família no processo de intervenção: de onde viemos e para onde devemos ir?
\end{tabular}

Fonte: Elaboração dos autores, 2021.

A cada seis meses, os palestrantes e ouvintes são convidados, através do canal de comunicação de WhatsApp do projeto, a participarem de uma avaliação das rodas de conversas, respondendo a um formulário elaborado pela comissão organizadora, no Google Forms, pontuando potencialidades e fragilidades. Tais dados são utilizados como mecanismo de avaliação do projeto pelo público-alvo, sendo um item demandado pelo sistema onde é registrado o projeto de extensão.

Quanto aos procedimentos éticos adotados na coleta de dados, apenas os membros da equipe têm acesso e mantêm a guarda das respostas dos formulários, comprometendo-se a manter sigilo quanto à identificação dos respondentes. O que será apresentado a seguir é um sumário dos resultados, com a finalidade de analisar de forma crítica o desenvolvimento do projeto. 
Dessa forma, existem dois formulários, sendo um específico para palestrantes, no qual as perguntas são direcionadas para os tópicos do cumprimento do horário, a plataforma de transmissão, a mediação e participação dos ouvintes. Já no formulário voltado para os ouvintes é questionado quanto aos temas abordados, palestrante e plataforma, além de apresentar sugestões de temas, no sentido de colaborar com o melhor desempenho desta atividade.

Para avaliação do projeto, foram propostas perguntas subjetivas e objetivas, sendo utilizado, para cada tópico objetivo no formulário, uma escala de 1 a 5 , com critérios prestabelecidos: (1) Muito insatisfeito; (2) Insatisfeito; (3) Neutro; (4) Satisfeito; (5) Muito satisfeito.

Até o momento da escrita deste artigo, 11 ouvintes e 4 palestrantes responderam aos formulários. Na Figura 1, a seguir, é possível visualizar os resultados referentes à avaliação dos palestrantes quanto ao projeto. Logo após, na Figura 2, é possível visualizar os resultados referentes à avaliação dos ouvintes quanto ao projeto. Ao lado esquerdo dos gráficos presentes nas imagens, estão registrados os aspectos avaliados. As colunas na horizontal, apresentadas em cores diferentes, registram quantas pessoas responderam cada pergunta, numa escala de 1 a 5 .

Gráfico 1 - Resposta dos palestrantes $(n=4)$ referente à avaliação da Roda de conversa virtual, quanto à participação dos ouvintes, à participação das monitoras, à mediação da roda de conversa virtual, ao cumprimento do horário e à plataforma de transmissão. Recife, 2021.

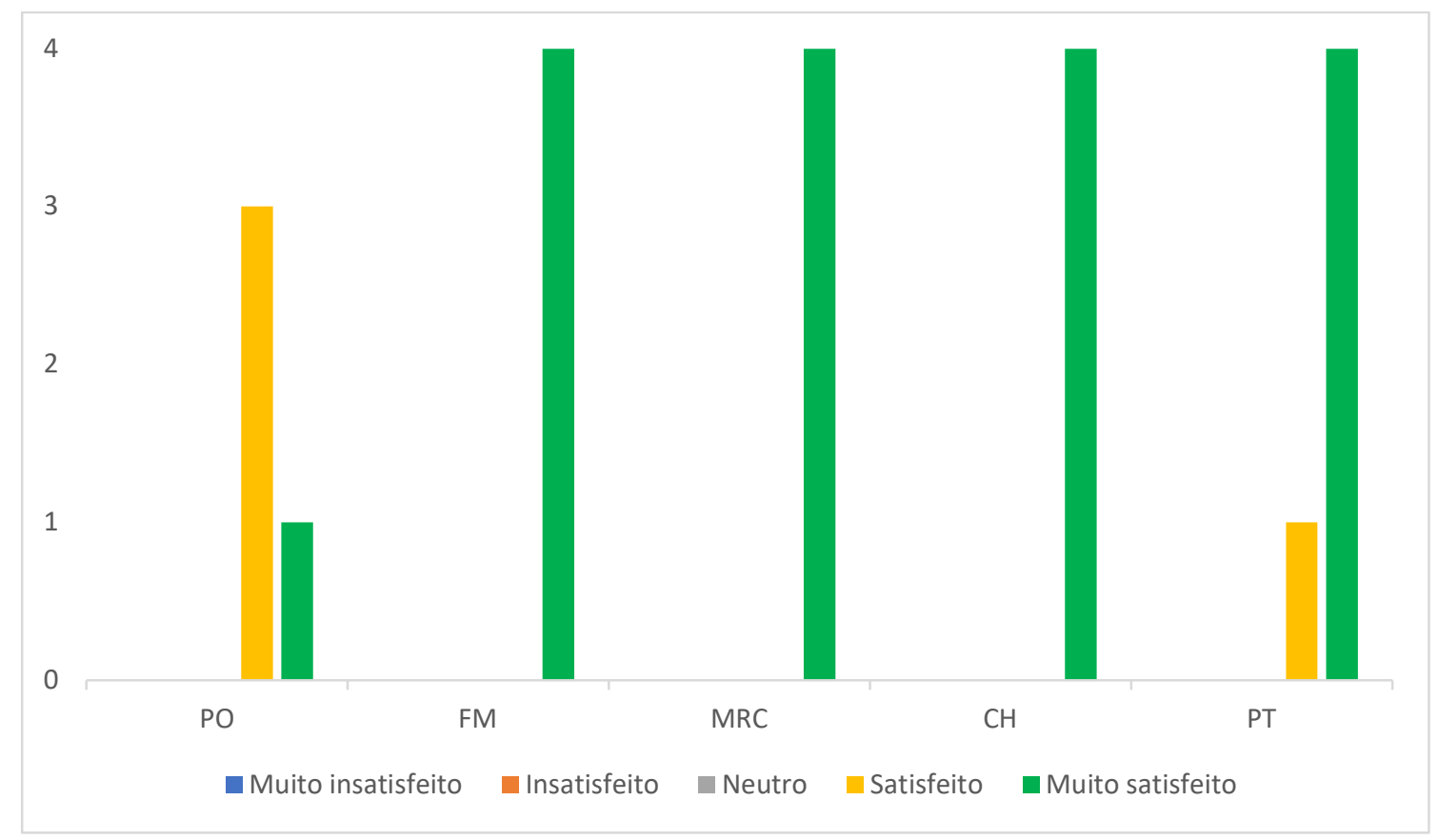

PO - Participação dos ouvintes; FM - Função das monitoras; MRC - Mediação da roda de conversa; $\mathrm{CH}$ Cumprimento do horário; PT - Plataforma de transmissão

Fonte: Elaboração dos autores, 2021. 
Gráfico 2 - Resposta dos palestrantes $(n=4)$ referente à avaliação da Roda de conversa virtual, quanto ao tema, ao palestrante do dia, à mediação da roda de conversa virtual, ao cumprimento do horário, à plataforma de transmissão e à função das monitoras. Recife, 2021.

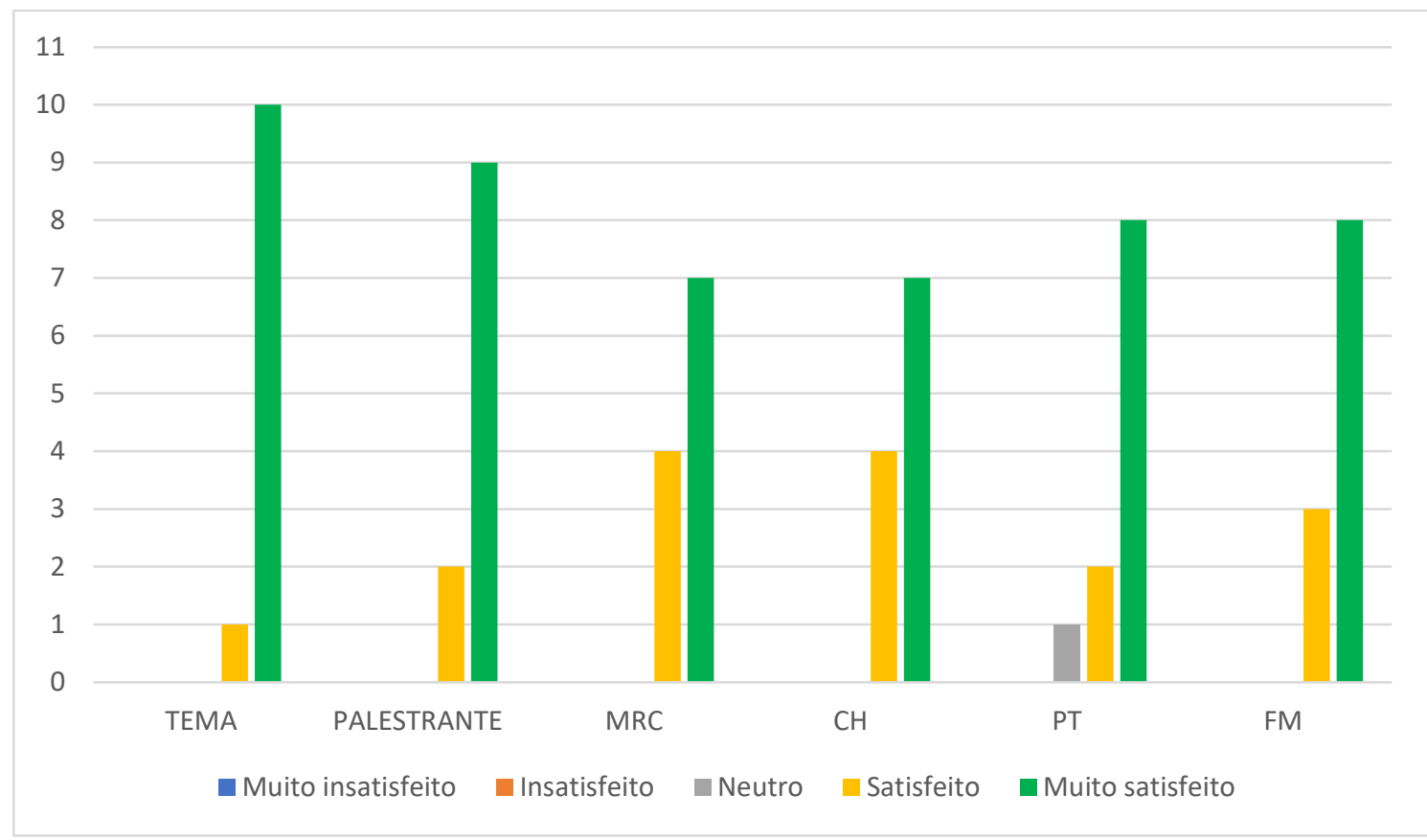

MRC - Mediação da roda de conversa; CH - Cumprimento do horário; PT - Plataforma de transmissão; FM Função das monitoras

Fonte: Elaboração dos autores, 2021

No que se refere às perguntas subjetivas do formulário, foram abordadas percepções sobre a iniciativa deste projeto de extensão (os/as respondentes foram identificadas pela letra "P" (palestrante): "Excelente!" (P1); "Muito necessária” (P2); "Muito boa para divulgar ideias e trabalhos" (P3).

Também foram identificadas opiniões dos ouvintes (os/as respondentes foram identificadas pela letra "O" (ouvintes) quanto à divulgação do projeto nas plataformas de redes sociais (WhatsApp e YouTube):

"Considerei muito importante o grupo no WhatsApp. Me sentir fazendo parte do projeto. E o Youtube para assistir aos dias que não participei” (O1);

“Achei boa a divulgação” (O2);

"Muito boa” (O3);

“As reuniões sempre são divulgadas com antecedência e há um lembrete no dia, assim como são salvas, então acredito que está sendo ótimo” (O4). 


\section{Discussão}

Os projetos de extensão apresentam a possibilidade de troca de conhecimentos entre as Instituições de Ensino Superior e a sociedade em geral. Nesse sentido, o projeto de extensão "Roda de Conversa Virtual: Dialogando entre os Saberes sobre o Desenvolvimento Infantil" tem se apresentado como um método possível de se debaterem temas por meio do diálogo, sem hierarquização dos presentes e reafirmando a participação de todos.

A partir dos resultados obtidos, é possível reafirmar o objetivo da criação deste projeto de extensão, quando, durante os encontros ou ao final de cada roda de conversa, cada participante pôde sentir-se capaz de difundir a discussão sobre cada assunto que é abordado, vinculando-o às realidades e demandas de cada público. Além disso, de viabilizar a criação de um contexto que facilita a comunicação e participação dos profissionais, discentes e docentes presentes na roda de conversa, com promoção de reflexão sobre os temas, comparando e inter-relacionando com os contextos de cada participante (AFONSO; ABADE, 2008).

Tendo como base a proposta de crescimento do conhecimento na área da saúde infantil e divulgação de estudos realizados por profissionais expertises em desenvolvimento da criança, nos seus diversos aspectos, o projeto pôde proporcionar a interligação entre saberes, provocando discussões e reflexões aprofundadas.

Para que um verdadeiro diálogo possa acontecer, é imprescindível a troca de experiências e a divulgação do conhecimento entre os envolvidos, pensando em construir e reconstruir saberes sobre o assunto abordado, através da escuta (MOURA; LIMA, 2014). Nessa perspectiva, por meio dos dados obtidos na avaliação realizada pelos palestrantes e ouvintes, foi possível realizar um apanhado de possíveis temas para os próximos encontros, como a ocupação e infância em tempos de pandemia; crianças em situação de vulnerabilidade social; vínculo materno-infantil e discussão sobre apraxia.

Assim, a partir das sugestões temáticas apresentadas pelos participantes das rodas de conversa, espera-se uma continuidade desta ação, tendo em vista o amplo campo de assuntos que envolvem a saúde e o desenvolvimento infantil, e que podem ser apresentados por profissionais terapeutas ocupacionais, incentivando o crescimento do conhecimento científico na área.

\section{Conclusão}

A extensão universitária é um compromisso de troca de saberes da universidade com a comunidade e, apesar do novo cenário que desafia e faz repensar sobre a criação de novas ações na extensão, é possível realizar um processo contínuo de ensino-aprendizagem virtual, onde acontecem trocas de saberes com o público universitário, docentes e profissionais, visando a futura aplicação prática do conhecimento teórico adquirido. E no caso deste projeto, 
especificamente, esse processo é realizado exclusivamente por Terapeutas Ocupacionais, profissionais e docentes que tenham experiência com o público infantil, envolvendo o público universitário (discentes e docentes de várias áreas), profissionais da Terapia Ocupacional e de áreas afins, além de pais e cuidadores.

O projeto já permitiu debates entre diferentes áreas de conhecimento da profissão quanto ao desenvolvimento infantil, viabilizando a oportunidade de contato com profissionais de outros lugares do Brasil. Vislumbra-se a continuidade da ação, necessária para se discutir, na área da Terapia Ocupacional, temas totalmente voltados à atualidade e à contemporaneidade, que tenham relação com a saúde infantil e seus desafios.

\section{Referências}

AFONSO, M.L.M.; ABADE, F. L. Para reinventar as Rodas. 1.ed. eletrônica. Belo Horizonte: Rede de Cidadania Mateus Afonso Medeiros (RECIMAM), 2008.

ASBJØRNSLETT, M.; ENGELSRUD, G. H.; HELSETH, S. How children with disabilities engage in occupations during a transitional phase. Journal of Occupational Science, v. 22, n. 3, p. 320-333, 2015.

ALBUQUERQUE, R.C. et al. Preferência visual cromática em recém-nascidos a termo. Cadernos Brasileiros de Terapia Ocupacional, São Carlos, v. 27, v. 2, p. 367-371, 2019. Disponível em: DOI: http://dx.doi.org/10.4322/2526-8910.ctoAO1774. Acesso em: 12 jul. 2021.

AZEVEDO, T.L; BARBA, P.C.S.D. Avaliação da estimulação e apoio no ambiente familiar oferecido à criança com paralisia cerebral. Revista de Terapia Ocupacional da Universidade de São Paulo, São Paulo, v. 28, n. 2, 198-205, 2017. Disponível em: DOI: http://dx.doi.org/10.11606/issn.2238-6149.v28i2p198-205. Acesso em: 12 jul. 2021.

BARBA, P.C.S.D. et al. Formação em vigilância do desenvolvimento infantil na atenção primária à saúde. Revista Brasileira de Iniciação Científica, Itapetinga, v. 4, n. 2, 36-54, 2017. Disponível em: https://periodicos.itp.ifsp.edu.br/index.php/IC/article/view/494. Acesso em: 12 jul. 2021.

BORGES, D. Ensino a distância na quarentena esbarra na realidade de alunos e professores da rede pública. BBC News Brasil, São Paulo. 11 de Maio 2020. Disponível em: https://www.bbc.com/portuguese/brasil-52568678. Acesso em: 16 jun. 2021.

CORREIA, L.A.; ROCHA, L.L.B.; DITTZ, E.S. Contribuições do grupo de terapia ocupacional no nível de ansiedade das mães com recém-nascidos prematuros internados nas unidades de terapia intensiva neonatal. Cadernos Brasileiros de Terapia Ocupacional, São Carlos, v. 27, n. 3, 574-583, 2019. Disponível em: DOI: http://dx.doi.org/10.4322/ 2526-8910.ctoAO1694. Acesso em: 16 jun. 2021. 
DUNFORD, C.; BANNIGAN, K. Children and Young people's occupations, heal thand well being: a research manifes to for developing the evidence base. World Federation of Occupational Therapists Bulletin, v. 64, n. 1, p. 46-52, 2011.

EMMEL, M. L. G.; FIGUEIREDO, M. O. Brincar, o desenvolvimento psicomotor e a aprendizagem. In: ENCONTRO DA ASSOCIAÇÃO BRASILEIRA DE PESQUISADORES EM EDUCAÇÃO ESPECIAL, 7., 2011, Londrina. Anais [...] Londrina, 2011. Disponível em: http://www.uel.br/eventos/congressomultidisciplinar/pages/arquivos/anais/2011/brincar/3632011.pdf. Acesso em: 16 jun. 2021.

FOLHA, D. R. S. C.; BARBA, P. C. S. D. Produção de conhecimento sobre terapia ocupacional e ocupações infantis: uma revisão de literatura. Cadernos Brasileiros de Terapia Ocupacional, São Carlos, v. 28, n. 1, p. 227-245, 2020. Disponível em: DOI: http://dx.doi.org/10.4322/2526-8910.ctoar1758. Acesso em: 16 jun. 2021.

FOLHA, D. R. S. C.; CARVALHO, D. A. Terapia Ocupacional e formação continuada de professores: uma estratégia para a inclusão escolar de alunos com transtornos do neurodesenvolvimento. Revista de Terapia Ocupacional da Universidade de São Paulo, São Paulo, v. 28, n. 3, p. 290-8, 2017. Disponível em: DOI:

\subsection{6/issn.2238-6149.v28i3p290-298. Acesso em: 16 jun. 2021.}

HALPERN, R. et al. Risk factors for suspicion of develop mental delaysat 12 months of age. Jornal de Pediatria. v. 76, n. 6, p. 421-428, 2000. Disponível em: DOI: http://dx.doi.org/ 10.2223/JPED.88 PMid:14647629. Acesso em: 16 jun. 2021.

KING T.M.; GLASCOE F. P.; Developmental surveillance of infant sand young children in pediatric primary care. Current Opinion in Pediatrics, v. 15, p. 624-629, 2003.

MANDICH, A.; RODGER, S. Doing, being and becoming: their importance for children. In: RODGER, S.; ZIVIANI, J. (Eds.). Occupational therapy with children: understanding children's occupations and enabling participation. Malden: Black well Publishing, 2006. 
MOURA, A. B. F.; LIMA, M. G. S. B. A reinvenção da roda: roda de conversa, um instrumento metodológico possível. Interfaces da Educação, Paranaíba, v. 5, n. 15, p. 24-35, 2014.

MUSSEN, P.H.; CONGER, J.J.; KAGAN J.; HUSTON A. C. Desenvolvimento e personalidade da criança. São Paulo: Harbra, 1977.

\section{Notas}

${ }^{\text {i }}$ O ComunicaTO é um projeto de extensão do Departamento de Terapia Ocupacional da Universidade Federal de Pernambuco que tem como intuito divulgar e compartilhar informações da Terapia Ocupacional no meio virtual. Entendendo que as redes sociais possuem grande implicação no dia a dia e que, atualmente, vivemos mais tempo conectados, o projeto é realizado através da página no Facebook e conta do Instagram.

ii Canal da plataforma YouTube: https://www.youtube.com/channel/UCP7K4apAxU8LSOnFYZooeDQ 